\title{
Meaning and purpose in the pursuit of physics teaching careers
}

\author{
Hunter G. Close \\ Department of Physics, Texas State University, 601 University Dr., San Marcos, TX, 78666
}

\begin{abstract}
Many factors enter into the decision to teach high school physics: scholarships and salary, working conditions and hours, professional preparation and support, job satisfaction, etc. Another element is how teaching might contribute to one's sense of meaning and purpose in life. To investigate the dynamic interplay between the path of teaching and the human spirit, I developed the "Journeys" interview protocol, which adapts archetypal forms from the hero's journey (Campbell, 1949) to the journey of earning a degree in physics and pursuing teacher certification; I used this protocol as a basis for discussion with four future physics teachers who are Noyce Scholars at Texas State University. This paper describes the development and content of the protocol and some of the initial results from interviews.
\end{abstract}

2019 PERC Proceedings edited by Cao, Wolf, and Bennett; Peer-reviewed, doi.org/10.1119/perc.2019.pr.Close Published by the American Association of Physics Teachers under a Creative Commons Attribution 4.0 license. Further distribution must maintain attribution to the article's authors, cover page, and DOI. 


\section{INTRODUCTION}

The shortage of qualified physics teachers has now been formally recognized for several decades, with the Physics Teacher Education Coalition (PhysTEC) in operation for almost 20 years [1]. During this period, PhysTEC has identified key components of successful physics teacher preparation programs and supported comprehensive sites at selected institutions of higher education, where these components have been enacted with creativity, critical examination, and attention to local institutional and cultural context. The coalition has had some definite success in beginning to address this long-term, large-scale shortage.

The Get the Facts Out (GFO) campaign [2, 3] has advanced the conversation around STEM teacher recruitment by identifying missing or incorrect information in perceptions about the teaching profession among students who might become K-12 STEM teachers and their university faculty. One aim of $G F O$ is to increase recruitment into physics teaching careers by properly informing stakeholders about physics teachers' salary, benefits, job satisfaction, etc.

However, my own experience as a former high school physics teacher and as a mentor to many future physics teachers (FPTs) over the years is that a significant part of the decision process for students is under-explicated in the broader conversation about physics teacher recruitment. I am going to call this missing piece the spiritual component. I suspect that by choosing the word spiritual to identify my premise, I risk losing some of the audience, though I believe ultimately it is the correct word. Here, spiritual does not refer directly to anything supernatural or formally religious. Instead I refer simply to the apparent spirit of each human person, which is that inner experience that is accompanied in most cases by a drive to live within a narrative that shapes a life with meaning and purpose. Whether a human spirit is ultimately an illusion of this or that sort in an objective sense is irrelevant; most of us certainly seem to be stuck with one.

In order to elicit the spiritual perspectives of FPTs, I turned to The Hero's Journey, a framework that was elaborated and popularized by 20th century mythologist Joseph Campbell [4] for understanding the dynamics of the human spirit through the course of life. The framework is an abstraction of common themes through analysis of a large collection of myths from various world cultures. Following this framework loosely, I developed an interview protocol for structuring my inquiries into FPTs' own sense of the narrative form of their journeys toward physics teaching thus far, and how this narrative might fit into a larger picture of their lives on the whole.

\section{A. Form and function of this paper}

A large portion of this paper is dedicated to presenting transcripts of segments of the interviews I performed. I do this because I believe it is important to hear from FPTs themselves what their motivations are, and how these motivations are woven together with other parts of their personhood. From a methodological perspective, it is also important to demonstrate the gentleness and patience in the interview style that I believe are necessary to elicit these reflections. Ultimately, this paper is meant to be useful to those researchers who wish to contemplate physics teachers' very personal, and often hidden, motivations for pursuing the work.

\section{BACKGROUND}

\section{A. Research on perceptions of the teaching profession}

GFO has found that students and faculty underestimate or are not aware of many positive aspects of K-12 STEM teaching. Many systematically underestimate teachers' salaries (especially in relation to non-tenure-track college teaching), extra earning opportunities, scholarship opportunities, loan forgiveness, and job satisfaction. The job satisfaction [5] data were collected in an electronic survey, and as might be expected, are limited in resolution to broad categories such as "intellectual challenge" and "level of responsibility". GFO has shown [6] that its MythBusters component is effective at improving the accuracy of information held by audiences over time and has enhanced student interest in K-12 teaching. Yet, there is still also clearly detail that can be colored in through deeper qualitative study.

\section{B. The hero's journey as psychological framework}

A foundational assumption of the analysis of myth is that the content and structure of myth is shaped largely by its alignment or applicability to fundamental concerns in human experience. One category of application of myth is to individual human development. The hero's journey has been adapted as a framework for human development in psychological counseling [7], social work [8], [9] and outdoor learning [10]. For example, Lawson [7] found that, for counseling clients, mapping elements of drama from heroic stories to one's own life could result in productive and healing reframings of various difficulties or failures encountered.

\section{INTERVIEW PROTOCOL}

\section{A. Design of protocol}

Even though the themes of the hero's journey have already been abstracted, the presentation remains somewhat metaphorical. For example, Campbell refers to the first two "steps" in the journey as The Call to Adventure and Refusal of the Call. Is teaching physics an "adventure", and are we "called" to it? To make the interview questions appear more innocuous and mundane, at least prima facie, I attempted to "de-mythologize" them further into the form shown in Table 
I. I also wanted the protocol to be fully accessible to all genders. Gender figures prominently in traditional myths and in Campbell's presentation, and contemporary scholars are critically examining [11-13] the role of gender in Campbell's and others' abstractions of myth. These criticisms did not appear to exclude the possibility of creating an all-gender-accessible formulation, which I hoped to achieve.

Some questions in the protocol correspond directly to some of the 17 "steps" in the journey, as presented by Campbell, while others attempt to probe students' relationships with the perennial "characters" in these dramas, without me assuming too much about how these psychological forces might have shown up for individuals or what effects they might have had.

In retrospect, the questions in the protocol might appear to be something that one could generate without this extra mythological baggage, which I then mostly stripped away. However, I believe that starting with the hero's journey helped me focus on psychological themes that interview subjects would likely find resonant, and which would frame the interview as one that would invite deep personal reflection.

\section{METHOD}

I recruited one graduate and three undergraduate students who were contemporaneously funded as Scholars by our Noyce teacher scholarship project. All four are FPTs, with either a major or minor in physics. The interviews lasted about 50 minutes and were video-recorded. I selected episodes for transcription with preference for those with greater depth of personal reflection.

\section{RESULTS AND DISCUSSION}

I present two long examples of discussion with Scholars S1 and S2 and summarize the interviews with all four Scholars, S1-S4, emphasizing the discussion of meaning and purpose.

\section{A. Example 1: Teaching expands human consciousness}

Scholar S1's response to question 1 led naturally into a discussion of meaning and purpose, with some right away and some as I circled back at the end of the interview.

Interviewer: (The first question is) about the decision to go into physics teaching. When would you say you decided that?

S1: I think I was expected to be a teacher because it comes with a status. And from very childhood, early, and

I: Expected by someone in particular?

S1: by my family

I: oh, your family

S1: This is a very good status, to be a teacher. it's a very, not like financially, but like, status
I: It's honorable?

S1: It's honorable, yeah, and teachers are respected, and religiously they will go all to heaven. Things like that.

I: OK.

S1: That was that, and then when I went into engineering physics, like my under(grad) degree is in atomic physics, and generally working in a lab with men and stuff, it wasn't very favorable with the culture of the day in Iran, so I guess being a teacher was the safest option. As in like in both ways, but I then wanted to become a teacher. In the qualification, was believing in the supreme leader of Iran and doing whatever he says, which is very informal and

I: In Iran, to be a teacher means to swear allegiance to the supreme leader of Iran?

S1: They don't ask you to actually raise your hand and say, like, say those things, but it's like in, like, being a journalist, being a lawyer, so many jobs, not only state jobs.

In the next excerpt, I circle back at the end of the interview to ask about the cultural idea that teachers go to heaven.

I: Maybe this is too intimate, but at the beginning you said that in Iran they believe that teachers go to heaven.

S1: $\mathrm{mm}-\mathrm{hmm}$

I: What's your personal view of that? Because I know you are a religious person.

S1: You have to have like a little bit background. So we Islam is a religion that believes that human being was created, not in seven days or anything. Like, it was created, Adam was not probably the first human being on Earth.

I: Is Genesis part of ... Islam?

S1: Yeah, there is a creation there, thing, yeah, but it's a lot different. It doesn't claim that there were no human beings on Earth when Adam was, and there was no seven day thingy. There is like levels, seven levels, of expansion of like, creation. But, so, and then after that, prophets were, messengers were chosen to lead the path, and those prophets, like, got more sophisticated as human beings became more sophisticated, so the very first messengers were very simple, like, and then Adam was a messenger himself. And then, so these were teachers. And so teaching is the job of a prophet. And then it comes to the last teacher who is prophet Muhammad.

At this point, S1 and I indulged in a tangent (for $\sim 70 \mathrm{~s}$ ) where S1 reviewed the different prophets and their special nicknames within the tradition of Islam. S1 then returned to explain the cultural value of being a teacher:

S1: So, yeah, there's this status, that teachers go to heaven. Yeah I do, I do think that whoever injects growth into society in any way, and... is probably, that's probably not a bad job, bad thing in the eyes of God. And also, it also comes with a culture that says 'teach kindness'. 
TABLE I. The Journeys interview protocol

\begin{tabular}{|c|c|}
\hline 1. Call & When did the choice to go into teaching first occur to you, and what was that like? \\
\hline 2. Refusal & Did you resist or deny this choice in any way? \\
\hline 3. Natural abilities & $\begin{array}{l}\text { a. What natural or innate attributes do you have that you think will work to your advantage as a teacher? } \\
\text { b. What natural attributes do you have that you think will work to your disadvantage? }\end{array}$ \\
\hline 4. Social structures & $\begin{array}{l}\text { a. What ways have you been shaped by the structures of society that you think will work to your advantage? } \\
\text { b. What ways have you been shaped that you think will work to your disadvantage? }\end{array}$ \\
\hline 5. Choices & $\begin{array}{l}\text { a. What choices have you made that have advanced you toward becoming a teacher, or a better teacher? } \\
\text { b. What choices have you made that have set you back? }\end{array}$ \\
\hline 6. Past challenges & $\begin{array}{l}\text { a. What challenges have you overcome that you count as your greatest successes? } \\
\text { b. What challenges have you encountered that you count as your greatest disappointments? }\end{array}$ \\
\hline 7. Helpers / obstructers & $\begin{array}{l}\text { a. Are there individuals in your life that have been especially encouraging or helpful to you for becoming a teacher? } \\
\text { b. Are there individuals that have discouraged you, stood in your way, or made the path more difficult for you? }\end{array}$ \\
\hline 8. Future challenges & Is there any challenge related to teaching that you are especially concerned about? \\
\hline 9. Meaning \& purpose & What does the path of becoming a teacher do for your sense of the meaning or purpose of your life? \\
\hline 10. Loose ends & Is there anything else that you would like to add to this conversation? \\
\hline
\end{tabular}

If you teach kindness through your lesson - this is a very old poem I'm reciting here - if you teach kindness throughout your lesson, you can bring back them even on a Sunday, like to school. They say the most escaping kid, you can bring them back, if you teach kindness. So, and kindness is also the principle of religion, so yeah, I think teacher, being a teacher is a very fulfilling job. Being a nurse should be the same, like religiously, but in my family, they say nope, the nurses stay in the hospital at night, and the girls should not stay at night, outside at night. It was always - I don't do good at the sight of blood anyway. But I was always like, nope, cannot be a nurse. Cannot be a nurse.

\section{B. Example 2: Sharing wonder at nature}

This example shows how Scholar S2 responded to question 9 in the protocol.

Interviewer: What does this path mean for you in terms of the ultimate meaning or purpose of your life? Is it connecting with that? Have you thought much about what you see your life as being about, or want it to be about? And is this doing it?

Scholar 2: I don't know what I want to do, broadly. But I have found something that I love to do. And I think I always want physics to be there. And I couldn't imagine myself doing something where I didn't do anything related to what I've been able to do here. So I don't know if I will always end up teaching, or if I'll always, or if I'll be an engineer, or maybe I'll just live in the woods in Colorado or something. But, if I wasn't able to do what I've found that I like here, I think I would be kind of sad.
I: So what is it about... I mean, so you must have a pretty open concept of the meaning and purpose of your life if you, if it might include living in the woods in Colorado, or it might include being an engineer. So what, is there a concept for your life that sort of captures those things?

S2: I really appreciate knowing how the world works. Or, not 'how it works', but having a larger knowledge compared to the average person. I like learning about that's why I like physics. It's like - everything. Everything that we've ever seen in the world. Every interaction we've ever had is physics. I like having an appreciation for the natural world. From, being an engineer, and building something, or designing something, or programming something, to living in the woods and just seeing the world work. Because it's all the same at some level. I think physics kind of ties everything, all of those ideas into one, like, subject, I guess.

I: So physics represents for you, the, um, it's like a gateway towards understanding the nature of the world, in its sort of ultimate or true form, or something?

S2: Obviously there's a lot more to that, but like at a very basic, excluding like consciousness and getting into like some weird - well, not weird - but more in-depth and not-as-concrete things. I guess there's a lot of physics that isn't very concrete, but. I just enjoy... I find wonder in it. At the (camp) place I work in the summer, they call it 'a sense of wonder'. We're supposed to foster a sense of wonder in the kids, to wonder about their natural world.

I: And can you explain why a sense of wonder is important to you, or does that feel like the bottom, fundamental, in terms of motivation for you?

S2: It fosters like a good meaning for, well, not a meaning for living. It's a good starting point for being a well- 
rounded person, is just wondering about things. Because you never know what you're gonna get by wondering about, or looking at, a leaf. And thinking about why things are happening in that leaf. Like the little bit, the tiniest little atoms that are moving around and doing stuff. You wonder, you think, you learn. It's just all very, it's a motivation like outside of, like, things that you need, it's more of like, a personal like, learning, I think it's important to wonder about things, whether it's like being... I'm confusing myself. It's a hard thing to explain I guess.

I: Is it important to you to help other people achieve a sense of wonder?

S2: $\mathrm{mm}-\mathrm{hmm}$

I: Why is that?

S2: um

I: Why not just go live by yourself in the woods in Colorado? And maybe you will.

S2: Maybe I will. Because I think it has broadened my horizons, I guess, and shown me a lot of different things, and shown me a lot of things that I'm interested in, and enjoy learning about. And it has made me, and all that kind of, I think it's just part of being a well-rounded person, is being able to question and be curious about things and wonder about things. And I, and then, in helping other people do that, especially younger kids, it kind of just, looking at it as like being set up to be a successful, curious, interested-in-things, that kind of person that is always out there trying to find answers and doing things.

I: And your motivation there is just, you know, you benefited, maybe they'll benefit, pass it on, type of thing?

S2: $\mathrm{mm}-\mathrm{hmm}$, a mutual, yeah. You should, I feel like it's important, I've found it is important. And I... don't think it's, like, important to just me. It's something that I could share it with other people that they could also see its importance in their lives. So I think that would make it a good reason to show people that other way of thinking - if they don't want to do that, I mean, that's fine, but I would like to show them, or maybe by asking them, we ask, they ask a lot of questions like 'you guys see that?', 'y'all notice that?' talk about it, because then maybe they'll do it themselves if they get the idea of that.

I: How old are these kids?

S2: um, there's a bunch, they're from 7 to 15 (years old).

I: And that part of your experience with them was positive enough that you thought, 'oh, I could do this in a building'?

S2: $\mathrm{mm}-\mathrm{hmm}$

I: You know, with similar-aged kids?

S2: Yeah, because I love the outdoors, and I love, like, backpacking, and horseback riding, and camping, and all that stuff... But I also love physics. And I like sharing my love of my outdoors things, but I also love sharing my love of physics things. And I think there's places for both of those to happen. So, teaching in a classroom in school is a great place because I think education is very important, and I think if you want to go live in the woods, that's fine, but I think you should always be trying to be educated, personally, it's important. But I see that, this part of me, being in school and getting a degree, just as important as the things I do outside of my education.

I: You see them complementing each other.

S2: Yeah. mm-hmm. Very much so.

\section{Summary of all four interviews}

The motivations expressed by all four Scholars were genuine and mutually distinct. As shown above, S1 expressed the importance of kindness and contributing to the growth of humanity over time; S2 saw the value of wonder at the world for being a healthy person. S3 related teaching to his experience as a restaurant server, and emphasized the fundamental importance of service to others. It is so important to him that he taught himself to visualize on demand a certain humorous image of the Hollywood actor Steve Buscemi so that he could always offer a smile in the physics help center. S4 was especially concerned about the preservation of certain vulnerable ecosystems and species, and wants to do as much as she can to save them, including working directly with them in addition to spreading concern for them among children through teaching. S1 and S3 both invoked their theistic (differing) religious traditions and yet had different emphasis (S1, kindness and growth of society; S3, service). S2 and S4 had nontheistic, naturalistic points of view and also had different emphasis ( $\mathrm{S} 2$, wonder, for the direct psychological benefit to the individual; S4, conservation, for the benefit of Earth's living systems). Every interview revealed that Scholars had motivations that transcend and include the important individual needs for salary, security, flexibility, etc., by attending to the needs or well-being of others and the world.

\section{CONCLUSIONS}

An interview protocol based on the major psychological themes highlighted by the hero's journey helped to invite prospective physics teachers into a deep personal reflection on their motivations for pursuing teaching. This approach revealed commonalities (transcending individual needs) and diversity (e.g., theistic/non-theistic, individual/collective). Continued invitation for present and future teachers to share these more intimate motivations may prove to be an important component of future K-12 STEM teacher recruitment efforts.

\section{ACKNOWLEDGMENTS}

This work is supported by NSF DUE 1557405. 
[1] American Physical Societyand American Association of Physics Teachers, Physics Teacher Education Coalition (2019).

[2] W. Adams, A New Survey Uncovers Strong Misperceptions About the Teaching Profession. What Can We Do to Get the Facts Out? (2017).

[3] W. K. Adams, M. Plisch, and T. Plantt, Have a passion for teaching? Consider high school teaching, American Journal of Physics 87, 328 (2019).

[4] J. Campbell, The Hero with a Thousand Faces, commemorat ed. (Princeton University Press, Princeton, NJ, 1949).

[5] American Institute of Physics, Job Satisfaction of Physics Bachelor's in High School Teaching Positions, Classes of 2011 \& 2012 Combined. (2015).

[6] K. Callan, W. K. Adams, and L. Cleveland, MythBusters: Interventions to Address and Correct Misperceptions About the Teaching Profession (2018).

[7] G. Lawson, The Hero's Journey as a Developmental Metaphor in Counseling, The Journal of Humanistic Counseling, Education and Development 44, 134 (2005).
[8] A. Willis, Re-storying wilderness and adventure therapies: Healing places and selves in an era of environmental crises, Journal of Adventure Education and Outdoor Learning 11, 91 (2011).

[9] J. Norris, Crossing the threshold mindfully: Exploring rites of passage models in adventure therapy, Journal of Adventure Education and Outdoor Learning 11, 109 (2011).

[10] L. Allinand B. Humberstone, Introducing 'Journey(s)' in adventure and outdoor learning research, Journal of Adventure Education and Outdoor Learning 10, 71 (2010).

[11] S. Nicholson, The problem of woman as hero in the work of Joseph Campbell, Feminist Theology 19, 182 (2011).

[12] J. Gelfer, Integral Spirituality or Masculine Spirituality?, Journal of Integral Theory \& Practice 4, 187 (2009).

[13] R. A. Bailin, Feminine, masculine, female, and male in the integral space, Journal of Integral Theory \& Practice 4, 89 (2009). 